\title{
In situ photoacoustic spectroscopic studies on heterogeneous catalysts under conditions of gas flow*
}

\author{
T SOMASUNDARAM and P GANGULY \\ Solid State and Structural Chemistry Unit, Indian Institute of Science, \\ Bangalore 560012 , India \\ MS received 31 March 1987
}

\begin{abstract}
An all-glass open photoacoustic cell through which gases can be passed without affecting the signal has been described. The cell has been characterized for various chopping frequencies and temperatures. Several heterogeneous catalytic reactions have been studied under conditions of gas flow at elevated temperatures and the potential application of this method in the field of heterogeneous catalysis has been pointed out.
\end{abstract}

Keywords. Photoacoustic spectroscopy; open photoacoustic cell; heterogeneous catalyst; catalytic reactions.

\section{Introduction}

In the last decade or so there has been a revived interest in the study of photoacoustic (PA) effect from condensed matter (Ganguly and Rao 1981; Tam 1986), after the pioneering work of Bell (1881) on the 'sonorousness' of the materials under the influence of intermittent light. This revival of interest was mainly due to the belief that the PA effect could be gainfully employed to obtain optical spectra of materials like gels and translucent solids which are normally inaccessible to the conventional spectroscopic techniques. Secondly it was believed that even thermal properties could be studied because of the dependence of the PA signal on thermal parameters. There have been several occasions where the belief has come true. Hence, there has been enormous growth since the revival in various branches of PA effect. Optical spectra have been recorded on powdered and light scattering materials (Monahan and Nolle 1977); thermal properties have been studied by Adams and Kirkbright (1977); phase transitions studied (Somasundaram et al 1986). Besides these applications there have been photoacoustic microscopic studies (Wickramasinghe et al 1978; Wong et al 1978), biological studies (Balasubramanian and Mohan Rao 1981) and surface studies (Low and Parodi 1980; Somasundaram et al 1987). The main advantage of using PAS for spectroscopic studies is the fact that the sample preparation is not very critical and in principle spectra can be recorded even from opaque solids. The disadvantages are the saturation effect and the difficulty in getting a quantitative measure of absorption coefficient $\beta$. Taking all these into account it was believed that the area of photoacoustic spectroscopy would be especially useful in the study of surfaces and more specifically those of catalysts which have high surface area. The high surface area of catalysts essentially increases the signal intensities (due to the possible increase in efficient heat transfer) and reduces the saturation effects.

\footnotetext{
*Communication No. 428 from the Solid State and Structural Chemistry Unit.
} 
One of the distinguishing features of PAS is that the positioning of the detector is not very crucial as far as the geometry with respect to the incident light is concerned. This flexibility of the detector position gives rise to the idea that perhaps the geometry of the cell may be changed so as to allow the study of catalysts under more realistic conditions. One such early study was by Kanstad and Nordal (1978) who proposed that a membrane could be used to separate the catalytic reactor cell from the microphone. The PA signal $\left(I_{P A}\right)$ generated in the reactor may then be transmitted to the microphone through the membrane. Others have proposed a design in which the catalyst could be transferred from the reaction chamber to the PA cell (Low and Parodi 1980). In all the studies the spectra were taken in a closed cell.

We have recently reported that gas-microphone PA signal may be recorded without significant loss of intensity even if the cell is open to the atmosphere or a gas is flowing through it (Ganguly and Somasundaram 1987). This suggests immediately that PA spectra may be obtained from a sample in situ under catalytic conditions. We have designed a cell in which we have been able to record PA spectra upto $800 \mathrm{~K}$, using a gas microphone, and study the spectra of catalysts under catalytic conditions. In this communication we report the characterization of an all-glass cell for the study at various frequencies and temperatures along with some of the experiments carried out by us using visible light. We believe the method will be of interest especially to those engaged in heterogeneous catalysis.

\section{Experimental}

\subsection{Description of the cell}

The cell used for this study shown in figure 1, has been fabricated from glass and consists of a cylindrical sample chamber of $15 \mathrm{~mm}$ dia and $6 \mathrm{~mm}$ height. Three capillaries are attached to the sample chamber each of roughly $15 \mathrm{~cm}$ in length. Two of these have internal diameter of $0.5 \mathrm{~mm}$ while the other has an internal diameter of $2 \mathrm{~mm}$. The last capillary is attached to the microphone. The smaller capillaries are used for gas inlet and outlet. The capillaries are joined to the sample chamber such that the sample (taken as a powder) is below the joints and the gas flow does not affect the sample in the sense that it is not blown out of the cell. With the dimensions given the signal amplitude is not changed by more than $5 \%$ when the cell is closed, open or when a gas is flowing through the cell for frequencies greater than or equal

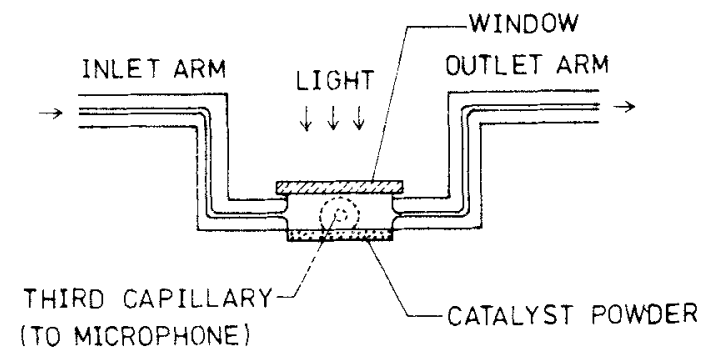

Figure 1. The all-glass open photoacoustic cell used for the catalytic studies under gas flow conditions. 
to $15 \mathrm{~Hz}$ (Ganguly and Somasundaram 1987). For frequencies lower than this there is a decrease.

The microphone connected to the sample chamber through the $2 \mathrm{~mm}$ dia capillary is GR 1961 electret condenser microphone. The microphone is in turn connected to a $x-y$ recorder through a lock-in-amplifier. The microphone has a flat frequency response. The cell is immersed in refractory alumina powder, inside a furnace, with the top of the cell kept clear for illumination. There is practically no signal from empty cell for wavelength $(\lambda)$ above $400 \mathrm{~nm}$ for all temperatures. Studies below $\lambda=400 \mathrm{~nm}$ carried out have taken into account the contributions from the cell and variations in the power spectrum. However, the results below $\lambda=400 \mathrm{~nm}$ are not quantitative, especially at high temperatures. The catalyst under study is taken as a fine powder and loaded into the sample chamber through one of the capillaries. For studies under catalytic conditions a gas such as nitrogen is passed after mixing with the vapours of the reactant. Care is taken to see that there is no condensation of liquids in the capillaries before and after reaction. In the studies described here the products have neither been analysed nor collected as the interest is only to study the changes in the catalyst and demonstrate the feasibility of PAS for studies under catalytic conditions.

\subsection{Characterization of the cell}

In figure 2 the frequency dependence of the signal is shown for carbon black powder. Between 10 and $100 \mathrm{~Hz}$ the signal from carbon black shows the expected inverse frequency dependence. Similar behaviour is seen even when a gas flows through the cell at $\sim 1.2 \mathrm{cc} / \mathrm{sec}$. The upturn at higher frequencies is associated probably with the onset of Helmholtz resonance. In figure 3 the intensity of the signal from carbon black at several temperatures is plotted against the reciprocal of the temperature.

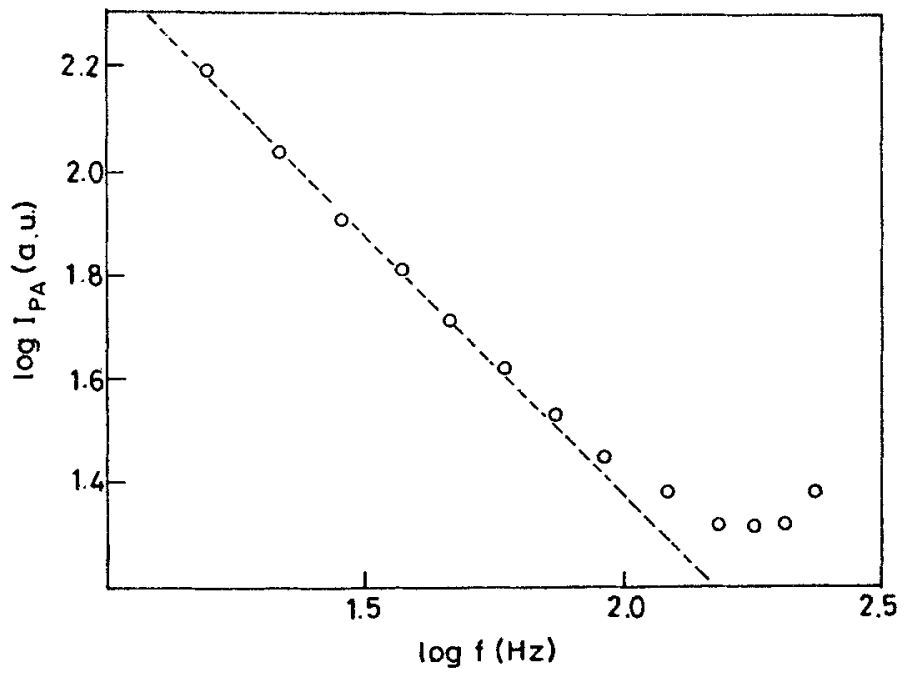

Figure 2. Frequency dependence of the PA signal of carbon black powder in the open PA cell under no gas flow condition. The dotted line shows the expected $f^{-1}$ dependence and circles represent experimental data points. 


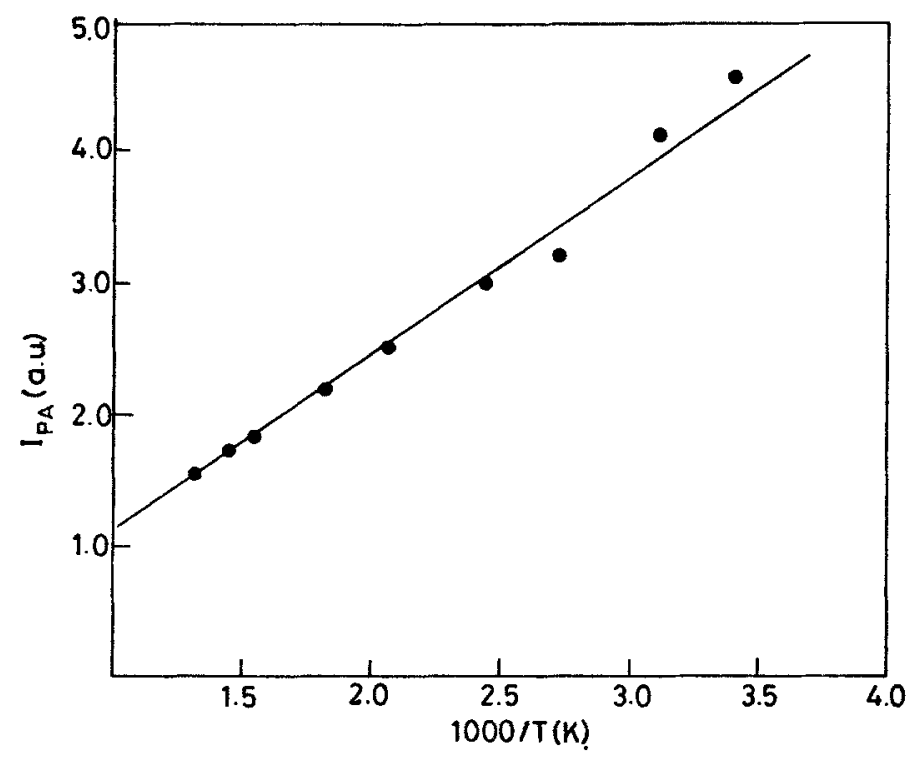

Figure 3. Variation of $I_{\mathrm{PA}}$ as a function of temperature for carbon black sample in the open PA cell under no gas flow conditions. The line is the best fit obtained for the data points.

The linear plot is in accordance with the currently accepted model due essentially to Rosencwaig and Gersho (1976). The power spectrum recorded at various temperatures is actually identical above $\lambda=400 \mathrm{~nm}$ except for the decrease in intensity as a function of temperature. These results show that the cell can be used for various studies without any difficulties. Even the Helmholtz resonance can be used successfully to enhance the signal if frequency dependence study is not required.

\section{Results and discussion}

\subsection{Studies with catalysts}

3.1a $\mathrm{CuO}-\mathrm{ZnO}$ : A catalyst with the nominal composition $\mathrm{Cu}_{0.2} \mathrm{Zn}_{0.8} \mathrm{O}$ prepared by the decomposition of nitrates has been studied in an atmosphere of $\mathrm{N}_{2}-\mathrm{CH}_{3} \mathrm{OH}$ (10:1 molar ratio) at various temperatures. The flow-rate of the mixture has been $1.5 \mathrm{cc} / \mathrm{sec}$. The spectra are independent of flow-rate and chopping frequency in the range studied (flow rates upto $\sim 2 \mathrm{cc} / \mathrm{sec}$ and chopping frequency $10-100 \mathrm{~Hz}$ ). Such independence is found with all the other systems studied. In figure 4 the spectra obtained at various temperatures in the presence of the reactant mixture are shown. The development of a feature around $500 \mathrm{~K}$ is similar to that observed by optical spectroscopy of these catalysts reduced at $250^{\circ} \mathrm{C}$ in hydrogen and attributed to the presence of $\mathrm{Cu}^{+}$species (Bulko et al 1979). At higher temperatures this band is missing and the intensity of the photoacoustic signal is independent of the wavelength below $400 \mathrm{~nm}$, perhaps due to the formation of metallic $\mathrm{Cu}$. The absorption at higher energies is probably due to $\mathrm{ZnO}$. 


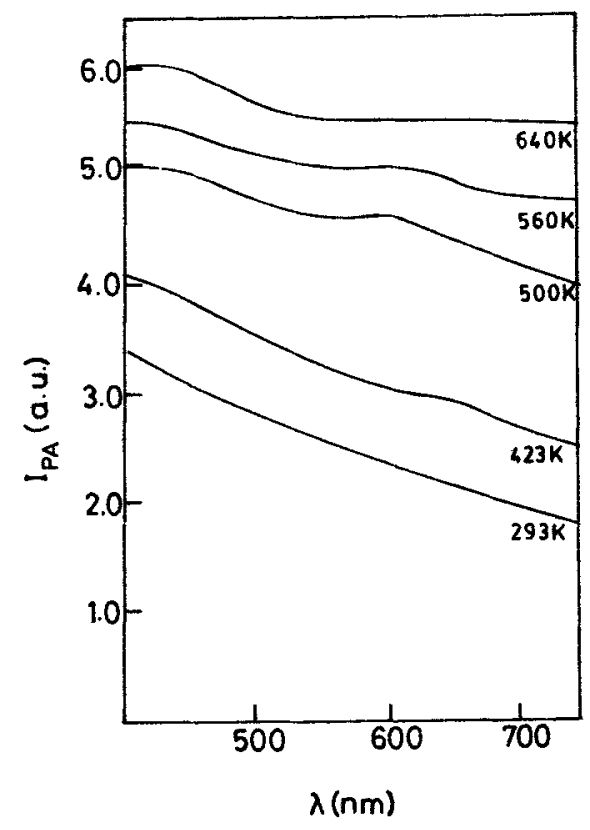

Figure 4. Normalized PA spectra of $\mathrm{Cu}_{0.2} \mathrm{Zn}_{0.8} \mathrm{O}$ catalyst under various experimental conditions. Flow-rate: $\sim 1.5 \mathrm{cc} / \mathrm{sec}$ of $\mathrm{N}_{2}-\mathrm{CH}_{3} \mathrm{OH}$ in the ratio 10:1. Temperature at which the spectrum is recorded is indicated against each curve.

-3.1b Acetone-alumina: An alumina catalyst (surface area $190 \mathrm{~m}^{2} / \mathrm{g}$ ) has been studied in the presence of acetone vapour at various temperatures. In figure 5 we show the PA spectra obtained in the presence of a flowing stream of acetone- $\mathrm{N}_{2}$ mixture (in the molar ratio $1: 8$ ). Curve $A$ in figure 5 is the spectrum of the catalyst alone at room temperature while curve $B$ is the spectrum in the presence of acetone. The increased signal below $400 \mathrm{~nm}$ in curve B must be attributed to the presence of acetone. When the temperature is raised, a prominent shoulder is seen around $350 \mathrm{~nm}$ at $370 \mathrm{~K}$. With further increase in temperature the catalyst attains a strawish brown colour which intensifies as the temperature is increased. The PA spectra at 400 and $500 \mathrm{~K}$ are shown as curves $\mathrm{D}$ and $\mathrm{E}$. The shoulder around $350 \mathrm{~nm}$ in curve $\mathrm{C}$ may be attributed to the formation of mesityl oxide (Rao 1967) which polymerizes further to give the yellowish brown product on the surface.

3.1c Chromia-alumina catalyst: In figure 6 the spectrum obtained from a $5 \%$ $\mathrm{Cr}^{6+}-\mathrm{Al}_{2} \mathrm{O}_{3}$ catalyst is shown. At room temperature the air-fired catalyst is yellow in colour due to the presence of $\mathrm{Cr}^{6+}$ ions. The PA signal at room temperature shows no features due to $\mathrm{Cr}^{3+}$ ions. The PA signal is saturated below $420 \mathrm{~nm}$ for the catalyst at room temperature. In the presence of a flowing stream of $\mathrm{N}_{2}$-isopropanol mixture (10:1 molar ratio) the spectrum is unaffected up to about $370 \mathrm{~K}$. The feature due to $\mathrm{Cr}^{3+}$ ion starts appearing around $400 \mathrm{~K}$. Around this temperature it is noticed that the signal shows a continuous increase below $400 \mathrm{~nm}$ instead of being saturated. This may be attributed to the formation of acetone. By recording the spectra of the effluent gas in another cell in which there is no catalyst one could 


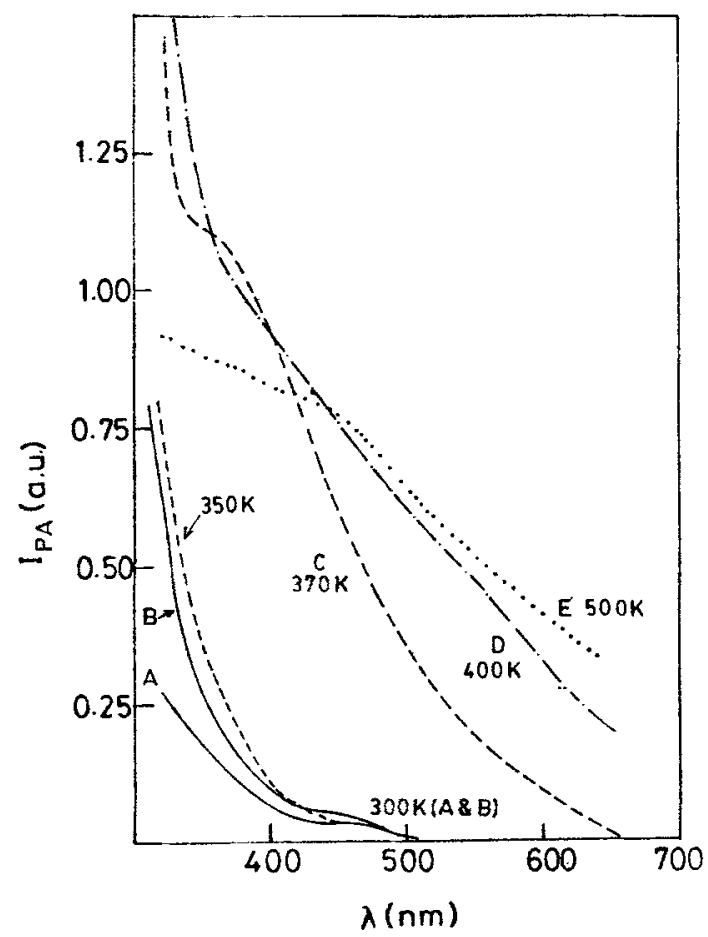

Figure 5. Normalized PA spectra of alumina catalyst under various experimental conditions. Flow-rate: $1.55 \mathrm{cc} / \mathrm{sec}$ of $\mathrm{N}_{2}$-acetone in the ratjo $8: 1$. A: catalyst only; B: catalyst with gas flow. The temperature at which the spectrum is recorded is indicated against each curve.

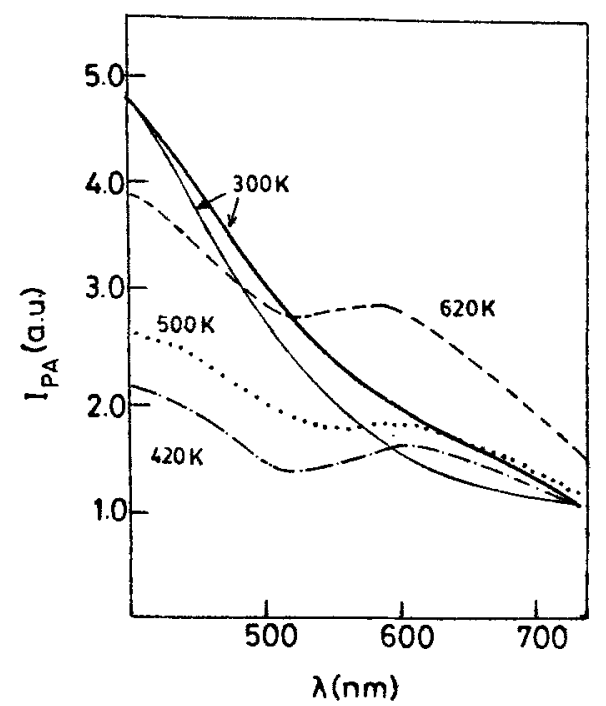

Figure 6. Normalized PA spectra of $5 \% \mathrm{Cr}^{6+}-\mathrm{Al}_{2} \mathrm{O}_{3}$ under various experimental conditions. Thin and thick lines represent catalyst and catalyst with gas flow at $300 \mathrm{~K}$, respectively. Flow-rate: $\sim 1.2 \mathrm{cc} / \mathrm{sec}$ of $\mathrm{N}_{2}$-isopropanol in the ratio $10: 1$. Temperature is indicated against each curve. 
ascertain whether the acetone is in the gaseous phase or adsorbed on the catalyst. With further increase in temperature the $\mathrm{Cr}^{3+}$ feature becomes more prominent and the charge-transfer band due to $\mathrm{Cr}^{6+}$ ion is much reduced in intensity.

\section{Conclusion}

The present study indicates the possibility of using PA spectroscopy for studying reactions under real catalytic conditions. By appropriately designing the cell, for example all quartz cell, even the UV region where most of the organic reactants absorb, can be studied at still higher temperatures. The difference between the adsorbed species and species present in the gas phase can also be made. These kind of studies are suitable especially for species which form only under the gas-flow conditions or decompose when the catalyst is cooled down to room temperature. By analysing the products either chemically or by attaching the PA spectrometer to a gas chromatograph the products of the reaction can be identified very easily. Further work is in progress on these lines.

\section{Acknowledgement}

One of the authors (TS) is thankful to CSIR, New Delhi for a fellowship.

\section{References}

Adams M J and Kirkbright G F 1977 Analyst (London) 102678

Balasubramanian D and Mohan Rao Ch 1981 Photochem. Photobiol. 34749

Bell A G 1881 Philos. Mag. 11510

Bulko J B, Herman R G, Klier K and Simmons G W 1979 J. Phys. Chem. 833118

Ganguly P and Rao C N R 1981 Proc. Indian Acad. Sci. (Chem. Sci.) 90153

Ganguly $P$ and Somasundaram T 1987 Proc. Indian Acad. Sci. (Chem. Sci.) (Communicated)

Low M J D and Parodi G A 1980 Appl. Spectrosc. 3476

Monahan E M and Nolle A W 1977 J. Appl. Phys. 483519

Kanstad S O and Nordal P E 1978 Opt. Commun. 26367

Rao C N R 1967 in Ultraviolet and visible spectroscopy (New York: Plenum) p. 18

Rosencwaig A and Gersho A 1976 J. Appl. Phys. 4764

Somasundaram T, Ganguly P and Rao C N R 1986 J. Phys. C19 2137

Somasundaram T, Ganguly P and Rao C N R 1987 Zeolites (in print)

Tam A C 1986 Rev. Mod. Phys. 58381

Wickramasinghe H K, Bray R C, Jipson V, Quate C F and Salcedo J R 1978 Appl. Phys. Lett. 33923

Wong Y H, Thomas R L and Hawkins G F 1978 Appl. Phys. Lett. 32538 